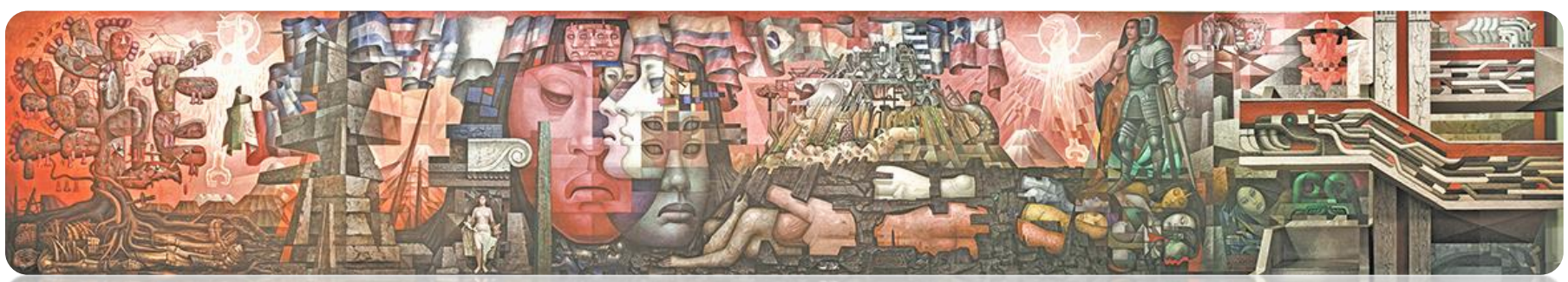

Rev. Hist., $N^{\circ} 28$, vol. 2, Julio-Diciembre 2021: 71-84

ISSN 0717-8832

https://doi.org/10.29393/RH28-27OSEC10027

\title{
O’Higgins y San Martín: concurrencia de tiempos y proyectos. Divergencias coyunturales, políticas y espaciales
}

\author{
O'Higgins and San Martín: convergence of times and projects. Conjunctural, political \\ and spatial divergences
}

Eduardo Cavieres Figueroa*

\section{RESUMEN}

¿Fue O’Higgins sólo un héroe nacional? Efectivamente, en términos de sus acciones militares y políticas propiamente tales, así lo es, pero en términos de su formación doctrinaria y voluntad americanista, su rol en la historia de los procesos de emancipación americana lo proyectan mucho más allá de las fronteras de la República a la cual dio nacimiento y primeras formas. Decididamente, su ideario político, republicano y americanista, le convirtieron en un prócer independentista de primera línea, lo cual quedó restringido historiográficamente al país al cual dedicó sus mayores esfuerzos. Ello le significó tomar las armas en el momento adecuado y dejarlas al momento de ejercer la magistratura del Estado al cual dio vida. No pretendió ir más allá, pero sí estuvo dispuesto a sumar sacrificios por la Independencia del Perú. La expedición libertadora fue una obra conjunta con San Martín que les unió en un solo objetivo, pero que les separó en cuanto a la forma de gobierno que allí debía instaurarse. Ni la amistad que le unía a San Martín, ni el respeto que le observaba, le disuadieron de optar por la monarquía en vez de la República. O’Higgins fue el héroe americano por principio y convicción: Repúblicas nacionales.

Palabras claves: República-monarquía, héroe nacional americanista vs. héroe americanista, Estado nación vs. Confederación americana.

\footnotetext{
*Premio Nacional de Historia (Q.E.P.D.).
} 


\begin{abstract}
Was O'Higgins only a national hero? Indeed, in terms of his military and political actions, he is, but in terms of his doctrinary education and his Americanist will, his role in the history of the American emancipation process projects him far beyond the limits of the Republic to which he gave birth. Undoubtedly, his political ideology, republicanist and Americanist, made him a front-line independence hero, but was, from the perspective of the historiography, restricted to the country to which he dedicated his greatest efforts. This meant that he took up arms at the right time and left them when exercising the magistracy of the State to which he gave life. He did not pretend to go further but was willing to add sacrifices to the Independence of Peru. The liberating expedition was a joint work with San Martin that united them under a single goal but put them apart in relation to the form of government to be established there. Neither the friendship that united him with San Martin, nor the respect he had for him, dissuaded him from opting for the monarchy instead of the Republic. O'Higgins was the American hero by principle and conviction: National Republics.
\end{abstract}

Keywords: Republic-monarchy, national americanist hero vs americanist hero, Nation state vs American Confederation

Recibido: septiembre 2021

Aceptado: diciembre 2021

\title{
Introducción
}

¿Se puede medir y comparar la grandeza y acciones de personajes históricos que han alcanzado la categoría de héroes y/o Padres de la Patria? La valorización que de ellos hacemos no sólo es diversa sino, además, cambia a través del tiempo. En el presente, para una gran mayoría, cada vez más alejada del pasado y de los orígenes, grandes momentos de la historia, o momentos fundacionales de la misma, tal como lo concebía el Estado Nacional de los siglos XIX y XX, parecen inexistentes o incluso, a menudo, con apreciaciones negativas. El fracaso del presente es el fracaso del pasado.

Los forjadores de los Estados y de las identidades nacionales de comienzos del siglo XIX en América Latina tuvieron un éxito innegable. Sus estados nacionales y sus historias nacionales a las que dieron lugar aún persisten y, al parecer, están lejos de agotarse en sus contenidos y funciones esenciales. Quizás a su pesar, con mínimas excepciones, esos propios forjadores, que tenían ideas bastante diversas a la imposición de fronteras inflexibles, fueron rápidamente nacionalizados y localizados en espacios nacionales determinados. 
Para entender a más cabalidad las situaciones sensibles escondidas detrás de los hechos históricos y de las narraciones historiográficas, José A. de la Puente Candamo, ha señalado que la llegada de San Martín al Perú es el inicio de la Independencia del Perú, pero que se le reconoce una significación muy secundaria a quién hoy se entiende como precursor. Nos preguntamos, ¿qué queda para Bernardo O’Higgins? Sabemos que no fue un actor directo y presencial, pero no se puede negar los esfuerzos que desplegó, y en muchos sentidos, a la gesta de emancipación. De la Puente Candamo piensa que dentro de los aportes de la literatura especializada para poner las cosas dentro de una más correcta mirada, uno de los alcances más importantes es el haber incursionado en la identidad del tiempo precursor lo que significa observar más detenidamente los pensamientos, temas de discusión, procesos, ideas y actitudes que precedieron (pero no desaparecieron) al momento de la ruptura con España. Así también están presentes el reformismo español como igualmente la crisis del Antiguo Régimen y su tránsito al tiempo liberal. San Martín, antes de salir desde Valparaíso para desembarcar en Paracas, conocía muy bien la situación intelectual, política, social y militar del Perú y el apoyo que obtendría a su llegada con un ejército relativamente pequeño. Resume: "es importante que el legítimo espíritu nacional que debe impregnar nuestra enseñanza de la historia del Perú, no olvide estas calidades americanas de nuestra lucha por la autonomía política"1.

En estos contextos, revisando acciones individuales y procesos sociales, ¿qué real significado y presencia actual tiene Bernardo O'Higgins en la historia nacional del Perú? Con más de alguna marcada diferencia, la misma interrogante cabe para el caso de José de San Martín. Nuestra intención no es el hacer comparaciones reales u odiosas entre ambos, sino más bien proyectarles en tres perspectivas de análisis: en el contexto de las transformaciones que incentivaron y permitieron los movimientos de independencia de las colonias españolas; en términos de sus pensamientos americanos y sus acciones revolucionarias, lo que significa, además, pensar en sus proyectos nacionales o americanistas y en formas de gobierno posible; $y$, en relación a sus logros y frustraciones.

\section{Los contextos}

La literatura existente sobre Independencia de los Estados de América Latina es abundante y diversa. El Prólogo escrito por José Luis Romero a la edición del Pensamiento Político de la Emancipación publicada por la Biblioteca Ayacucho, nos entrega una serie y un conjunto de ideas que, siendo conocidas, están presentadas con alta coherencia y precisión, subrayando siempre relaciones esenciales que orientan a la percepción y significado de cuestiones sin las

\footnotetext{
1 Puente Candamo, José A. de la. 2001. "La historiografía peruana sobre la Independencia en el siglo XX", en: O’Phelan G., Scarlett (Comp.) La independencia del Perú. De los Borbones a Bolívar, Lima, Instituto Riva Agüero, PUC, p.17.
} 
cuales no podríamos tener una imagen acabada tanto del proceso general, como de los particulares, en los cuales debemos entender a nuestros personajes principales ${ }^{2}$.

Nos dice que la nueva realidad se definió a través de una suma de contradicciones surgidas desde guerras civiles, vagos movimientos sociales, controversias constitucionales, luchas de poder:

"Instantáneamente, el movimiento emancipador debió hacer frente a los conflictos de intereses. Entre quienes propiciaban la libertad de comercio, algunos -especialmente en los centros claves del comercio colonial- procuraban subrepticiamente conservar para sí, dentro del nuevo régimen, algún tipo de monopolio o de ventaja. Contra esa tendencia se levantaron Artigas en la Banda Oriental y el Doctor Francia en Paraguay, ambos dispuestos a quebrar la absorbente preponderancia comercial de Buenos Aires. De hecho, buena parte de las razones que en otras regiones de América estimularon los movimientos federalistas obedecieron a las mismas razones" ${ }^{\prime 3}$.

Contra ello, el Constitucionalismo fue casi una obsesión desde el primer momento. Despierta con fuerza irreprimible el sentimiento de nacionalidad. Estado de conciencia colectivo, difuso, pero de vehemencia. La idea de nación se nutre de la idea de patria. Cada nuevo país se concentró en su propia personalidad colectiva, en sus hombres y en sus paisajes, y de cuanto la diferenciaba de los demás.

Esta situación, legitimada en la historia política del siglo XIX y en el nacionalismo cultural del siglo XX, puso al Estado nacional como centro de todo, oponiéndose en la práctica a la vieja idea de nación americana o de patria grande. Con las tendencias centralistas, por una parte, y la unificación de tres países en Colombia, por otra, se mantuvo por un tiempo la tensión. Más aún, señala Romero,

"la retirada de San Martín después de la entrevista de Guayaquil, la debilidad de los países del área del Plata sumidos en la guerra civil y el éxito de los ejércitos bolivarianos en Bolivia y Perú, parecieron asignar posibilidades reales a aquel ideal de la unidad americana. Empero, el sentimiento nacional y los intereses locales se mostraron suficientemente activos como para descubrir que la idea no era factible. Bolívar se mantuvo, sin embargo, fiel a ella, y poco después que terminaron las luchas por la Independencia convocó al Congreso Anfictiónico de Panamá. El tiempo había pasado, y la línea predominante de las nacionalidades condenó al fracaso de una aspiración tan sublime como utópica" ${ }^{4}$.

\footnotetext{
2 Romero, José Luis. 1985. Prólogo, en: Pensamiento Político de la Emancipación, 1790-1825 [1977], Barcelona Biblioteca Ayacucho.

${ }^{3}$ Ibídem, pp. XXVI, XXVII, XXXII y XXXIII.

${ }^{4}$ Ibídem, p. XXXVII.
} 
Como es bien sabido, Bernardo O'Higgins, en su estadía en Londres, como discípulo de Miranda y con la influencia de éste, se supone que tenía una visión americana de las transformaciones, pero los pasos y caminos que quiso o debió seguir, lo llevaron a un territorio bastante más restringido que aquellos espacios a liberar en sus conversaciones con su mentor. A nivel americano, no ocupa en las preocupaciones de los historiadores ni en las páginas de la historia, un lugar predominante, ni por ideas ni por acción, pero sin duda se encontró con lo que debía resolver. Bartolomé Mitre, sintetizó en forma precisa la situación: afiliado además a la logia de Miranda, “O’Higgins debía ser más tarde el vínculo indisoluble de la alianza argentino-chilena, durante la guerra de la independencia, simbolizada entonces por su unión con el argentino Rozas. Así se eslabonaban en un oscuro rincón de la extremidad de la América Meridional sus futuros destinos" ${ }^{\prime 5}$. Por cierto, los futuros y comunes destinos con San Martín. No obstante, podemos preguntarnos si O’Higgins buscó el campo de batalla y la primera gubernatura del país, o si éstas le buscaron. La respuesta inequívoca es que no intentó esquivar el rol que tenía asignado.

Lo de San Martín es diferente. Como soldado argentino, John Lynch lo definió como héroe americano y, sin usar la misma relación, la mayoría de los latinoamericanistas coinciden en ello. Quizás menos preparado filosófica o políticamente que don Bernardo, sí tenía horizontes claros y definidos. Solicitó la gobernación de Cuyo y las autoridades de Buenos Aires se la concedieron. En septiembre de 1814 se estableció en Mendoza y ya tenía en mente que debía crear y organizar el Ejército de los Andes. Su vista llegaba al mismo Perú. Tenía suficientemente asumido que la ruta septentrional al virreinato estaba cerrada por el terreno, la altitud, las temperaturas extremas, la falta de recursos y la hostilidad de la población local: el Alto Perú se había establecido como una barrera en el camino hacia Lima. La única posibilidad era cruzar a Chile y subir al Perú por el Pacífico ${ }^{6}$. Todo conducía a su relación aún no consolidada con O’Higgins. La coyuntura del desastre de Rancagua de 1814 facilitó todo lo que vino.

Para O'Higgins, los contextos de época y su propia formación en Inglaterra le hacían pensar en una transformación profunda del antiguo régimen, en un desarrollo liberal para América Latina y en un proyecto cuyos marcos teóricos y posibilidades prácticas pudo compartir y profundizar con el no siempre reconocido Rozas, intermediario importante entre la organización política de ambos lados de la cordillera. Para San Martín los contextos de época y sus propias experiencias de vida le llevaban a pensar, igualmente, más allá de sus propias fronteras. Interesaba la ruptura del orden colonial y eso era la prioridad. A 10 o menos años plazo, ambos no podían considerar los rumbos que seguirían "las y sus" historias. O’Higgins se centró en la construcción de un Estado Nacional e independientemente del carácter de su

\footnotetext{
${ }^{5}$ Mitre, Bartolomé. 2011. Historia de San Martín y la emancipación sudamericana [escrita en 1869 y editada en 1887], Buenos Aires, Editorial El Ateneo, p. 154.

${ }^{6}$ Lynch, John. 2009. San Martín. Soldado argentino, héroe americano, Madrid, Crítica, pp. 105-109.
} 
gobierno, no dejó de ser liberal. San Martín miró mucho más allá de limitadas fronteras nacionales y, sin duda, presionado por las realidades, pensó en la opción monárquica. Jorge Basadre recoge que, en agosto de 1821, San Martín señalaba que «la experiencia de diez años, el imperio de las circunstancias, le habían enseñado a conocer los males de gobernar la América por medio de la expresión de la voluntad nacional antes de estar asegurada la Independencia" y ello se recoge en la primera y segunda etapa de su monarquismo peruano cuando de acuerdo "a las circunstancias", firmaron, entre otros, la representación para llegar a un acuerdo amistoso tendiente a la elección de un príncipe español Hipólito Unanue, Justo Figuerola, el Conde de Vista Florida (Salazar y Baquijano) y otros personajes que actuaron en la Independencia. El mismo historiador peruano señala que, basándose en la amistad entre O’Higgins y San Martín, "hubo intentos de asociar al primero a sus planes monárquicos, tan infructuosamente como antes había sido la gestión de Irrisari con el mismo objeto" ${ }^{7}$.

\section{Pensamientos americanos y acciones revolucionarias}

El Ejército Libertador de los Andes, para otros, más ampliamente, el Plan Continental de San Martín, ¿tuvo un autor?, ¿fue un proyecto concertado?, ¿surgió naturalmente guiado por las circunstancias y coyunturas que debían enfrentarse? Los historiadores, en su gran mayoría, no abordan el origen intelectual, si es que así se puede llamar desde un modo específico, y quizás no es necesario hacerlo, particularmente ya que, en términos generales, la historiografía releva más el papel de San Martín y porque, además, al pensarse en la gesta a nivel hispanoamericano, se conceden mayores créditos a don José, especialmente, porque ya desde 1814 (y antes) O'Higgins se había "nacionalizado" respecto a la Independencia de Chile propiamente tal y en los años siguientes dirigió su formación como Estado. Más aún, San Martín, para poder aplicar el proyecto, participó igualmente en la política y en la gestión bélica en Chile.

Entre 1810 y 1812, los complejos hechos y rivalidades en Buenos Aires fueron bastante locales, lo cual comenzó a cambiar drásticamente en 1812. A ese año, los primeros movimientos independentistas habían desembocado en la formación de un triunvirato con fuerte inclinación hacia un centralismo porteño. Fue cuando se hizo presente el movimiento de la Sociedad Patriótica encabezada por la Logia Lautaro con José de San Martín y Carlos Alvear que habían desembarcado en la ciudad a comienzos de ese año. El mismo triunvirato había nombrado a San Martín para organizar un cuerpo de granaderos para la vigilancia

\footnotetext{
7 Basadre, Jorge. 2002. La iniciación de la República [1929], Lima, Clásicos sanmarquinos, Fondo Editorial de San Marcos, p.69.
} 
costera $^{8}$. Como está señalado, los objetivos del héroe cuyano eran tener una moderada independencia de Buenos Aires y en 1814 era gobernador de Cuyo con su principal propósito de pasar a Chile para iniciar su mencionado proyecto de expedición hacia el Perú. Más que nacionalizarse en los ámbitos de lo que sería Argentina, su misión siempre fue amplia y americanista y aun cuando no pudo o no quiso competir con Bolívar, de todos modos en la historiografía siempre merece un lugar preponderante a nivel continental.

En los fundamentos más profundos de la gesta americana, Bernardo O'Higgins no queda atrás. Compartía con San Martín, además, el ser miembros de la controvertida Logia Americana y compartir una visión común respecto a una nueva organización socio-política de las ex - colonias. Mitre escribió una adecuada síntesis en lo que unió a ambos héroes: El lanzarse la República Argentina a la empresa de la reconquista de Chile, obedeció a tres tendencias principales: "la defensa propia como móvil, el dominio del Pacifico como medio, la emancipación de América del Sur como fin. San Martín era el alma de la alianza, que le infundía su espíritu; O’Higgins el vínculo internacional (y) la garantía por parte de Chile; el ejército de los Andes, su nervio y su musculatura, y la Logia de Lautaro, su mecanismo secreto. Indudablemente, entre ellos existía complicidad. En 1816, cuando desde Buenos Aires se comunicó a San Martín que no se podía disponer de la suma requerida para el Ejército Unido, éste presentó su renuncia. O'Higgins, profundamente impresionado, le escribió: "iCuando me preparaba a estrecharlo en mis brazos, recibo la amargura de su resignación! San Martín es el héroe destinado para la salvación de la América del Sur, y no puede renunciar la preferencia que la Providencia eterna le señala" ${ }^{\prime}$.

Hacia 1820, sin perder la sensación de poder buscar un ambiente favorable a un americanismo que uniera a los nuevos Estados en formación, a lo menos en el Cono sur, las ideas nacionales ya eran fuertes y los proyectos comunes de traspasar fronteras para la consolidación de las independencias eran cuidadosos de no suponer algún tipo de dominación militar. En septiembre de 1820, O’Higgins escribió a los peruanos:

"Ha llegado el día de la libertad de América, y desde el Mississipi hasta el Cabo de Hornos, en una zona que casi ocupa la mitad de la tierra, se proclama la independencia del nuevo mundo... Ilegó la época destinada por el Dios de la Justicia y las misericordias a la felicidad el Perú, y vuestros hermanos de Chile han apurado sus últimos sacrificios para protegeros con una escuadra respetable, que asegurando estas costas, os presente recursos en todos los puntos donde escuche vuestras necesidades y el sagrado clamor de la libertad.

\footnotetext{
${ }^{8}$ Al respecto, la historiografía es muy amplia; en este caso, ver, por ejemplo, Romero, José Luis. 1965. Breve historia de la Argentina con continuas reediciones, la 8a , 2009, Buenos Aires, FCE, pp. 49-61; también Gelman, Jorge (Dir. y Coord.). 2010. Argentina. Crisis imperial e independencia, Madrid, MAPFRE, pp. 64-74.

${ }^{9}$ Mitre. "Historia de San Martín", p.402.
} 
Inmediatamente ocupará también vuestro suelo un respetable ejército de los valientes de Maipú y Chacabuco, destinado a consolidar el goce de vuestros derechos.

Peruanos: He aquí los pactos y condiciones con que Chile, delante del Ser Supremo, y poniendo a todas las naciones por testigos y vengadores de su violación, arrostra la muerte y las fatigas para salvaros.

Seréis libres e independientes; constituiréis vuestro gobierno y vuestras leyes por la única y espontánea voluntad de vuestros representantes. Ninguna influencia, militar o civil, directa o indirecta, tendrán estos hermanos en vuestras disposiciones sociales.

Hijos de Manco-Capac, Yupanqui y Pachacutec: estas sombras respetables serán los garantes de las condiciones que por mi voz os propone el pueblo de Chile, así como la de alianza y fraternidad, que os pedimos para consolidar nuestra mutua independencia, y defender nuestros derechos el día del peligro"10.

San Martín, quizás por el mismo rol que jugaba e incluso en una doble interpretación de objetivos, tiempos de formación ciudadana, divisiones internas, etc., fue suma y explícitamente respetuoso de los derechos soberanos de los pueblos en nombre de los cuales sentía que debía actuar. En Chile, incluso, se le ofreció el poder supremo: lo rechazó tanto por sus lealtades hacia O'Higgins como por su profundo compromiso de seguir hacia el Norte. En este sentido, son muchas las expresiones que dejó registradas:

"Después de una batalla completa en el campo de Maipú, sin escuchar ni el sentimiento de la más justa venganza por una bárbara agresión, ni el derecho de la indemnización por los graves males causados a Chile, di una completa prueba de mis sentimientos pacíficos... Después de la jornada de Chacabuco... El ejército español fue enteramente derrotado, Chile se hizo un Estado independiente, y sus habitantes empezaron a gozar de la seguridad de sus propiedades y de los frutos de la libertad ${ }^{11}$.

Al encargarme de la importante empresa de la libertad de este país, no tuve otro móvil que mis deseos de adelantar la sagrada causa de la América, y de promover la felicidad del pueblo peruano... -comprometo mi palabra - ofreciendo solemnemente a los pueblos del Perú que en el momento mismo en que sea libre su territorio, haré dimisión del mando para hacer lugar al gobierno que ellos tengan a bien elegir..."12.

En junio de 1822, San Martín inicia el viaje para la controvertida entrevista de Guayaquil con Bolívar. John Lynch, como tantos otros historiadores, es cauto y trata de no involucrarse

\footnotetext{
${ }^{10}$ Bernardo O'Higgins: A los habitantes del Perú, setiembre de 1820, en Romero, José Luis. 1985. Pensamiento Político de la Emancipación, T.2, pp. 203 y 204.

11 José de San Martín: A los limeños y habitantes de todo el Perú, 13 noviembre 1818, en Romero, José Luis. 1985. Pensamiento político de la Emancipación, T. 2. Pensamiento político de la Emancipación; T. 2, p.150.

12 José de San Martín: Proclama de despedida, 22 setiembre 1822; en Ibídem, T.2, p.166.
} 
con juicios definidos. Aun así, señala que "Bolívar odiaba la idea de arriesgar su gloria llegando en segundo lugar, (pero que) el Protector del Perú no estaba por encima del Libertador de Colombia... San Martín no era tan agudo. De hecho, se había demorado en entender los indicios y había sido demasiado cauto a la hora de formular su política en relación a Guayaquil"13.

Después de la entrevista, grandeza de espíritu o aceptación de la derrota sin arriesgar de su cuenta la débil tranquilidad alcanzada en el Perú. En ambos casos, más que un gran personaje, una gran persona. Palabras con historia:

"Un encadenamiento prodigioso de sucesos ha hecho ya indubitable la suerte futura de América; y la del pueblo peruano sólo necesitaba de la representación nacional para fijar su permanencia y prosperidad... Si mis servicios por la causa de América merecen consideración al Congreso, yo los represento hoy, sólo con el objeto de que no haya un solo sufragante que opine sobre mi continuación al frente del gobierno ${ }^{14}$.

Presencié la declaración de la independencia de los estados de Chile y el Perú: existe en mi poder el estandarte que trajo Pizarro para esclavizar el Imperio de los incas, y he dejado de ser hombre público; he aquí recompensados con usura diez años de revolución y guerra.

Mis promesas para con los pueblos en que he hecho la guerra están cumplidas: hacer su independencia y dejar a su voluntad la elección de sus gobiernos" ${ }^{\prime 15}$.

\section{Logros y frustraciones}

Para Simón Bolívar y José de San Martín, la libertad de cada nación dependía de la liberación total del continente, es decir, estaba subordinada a la suma de todas las naciones emergentes. Después de Guayaquil, el componente continental se identifica exclusivamente con la corriente bolivariana: "ya en los años después de 1822, ligado al viraje de la mayoría aplastante de los criollos, antes indiferentes, se profundizó visiblemente la tensión entre la corriente continental y la creciente -nacionalización- de la Independencia"16.

Cuando San Martín se pone en marcha en 1817 con el Ejército de los Andes estaba previsto por Pueyrredón que aquél tendría que sembrar naciones... ¿̇se había renunciado en el sur a la Gran Nación cuando en el norte la hacía realidad Bolívar? Bolívar temía por ella y presumía la instalación de San Martín como monarca: "poco podemos adelantar sobre lo ya conocido del propósito de San Martín, pero no creemos que Bolívar estuviera descaminado en sus

\footnotetext{
${ }^{13}$ Lynch, "San Martín. Soldado argentino", p. 269-276.

14 José de San Martín, Proclama al Congreso Constituyente dimitiendo el mando supremo, 20 septiembre 1822, en Romero, José Luis. 1985. Pensamiento político de la Emancipación, T.2, p.163.

15 José de San Martín, Proclama de despedida, 22 septiembre 1822, en Ibídem, T.2, p.166.

${ }^{16}$ Kossok, Manfred. 1984. "Revolución, Estado y Nación", en Inge, Buisson(ed.), Problemas de la formación del Estado y de la Nación en Hispanoamérica, Bonn, InterNations, p. 165.
} 
temores". El 6 de mayo de 1818, tras Maipú, San Martín proclamó la necesidad "de que las naciones libres de América constituyeran la Gran Confederación del Continente, capaz de sostener la libertad política y civil” ${ }^{17}$.

La lógica de la historia se cumplió en los dos libertadores, como caudillos de las dos hegemonías que representaban en acción y en conflicto. San Martín cedió el puesto a Bolívar... Bolívar coronó la obra, y los dos triunfaron, en definitiva. San Martín miró sin envidia que Bolívar, con quien compartía la gloria de libertar la mitad de medio mundo, alcanzase y mereciere la corona del triunfo final. El destino de los emancipadores de acción y pensamiento de la América meridional es trágico. Los precursores de la revolución en la Paz y Quito murieron en los cadalsos, asesinados o en el destierro. Miranda, Moreno, Belgrano... O’Higgins, el héroe de Chile, acabó sus días en la proscripción, precedido por Carrera, su rival y su colaborador, a quien la fatalidad arrastró al cadalso en tierra extraña... Iturbide, Montufar, Villavicencio, Jorge Tadeo Lozano y Camilo Torres, Piar, Rivadavia, Sucre... Bolívar y San Martín murieron en el ostracismo. El de San Martín fue acto deliberado de su voluntad, aunque impuesto por su destino. El de Bolívar, aunque pronunciado por él mismo al agotarse sus fuerzas vitales, empezó con su apogeo y terminó con su catástrofe ${ }^{18}$ :

“... En el orden definitivo de las cosas, el triunfo de los principios elementales de la revolución sudamericana corresponde a San Martín, aunque la gloria de Bolívar sea mayor... La obra política de Bolívar en el orden nacional e internacional ha muerto con él, y sólo queda su heroica epopeya libertadora a través del continente por él hecho independiente. La obra de San Martín lo ha sobrevivido, y la América del Sur se ha organizado según las previsiones de su genio concreto, dentro de las líneas geográficas trazadas por su espada"19.

\section{Consideraciones finales: una incipiente y frustrada idea de integración panamericana}

Cuando se revisa la abundante historiografía concerniente directamente a los principales héroes de la independencia latinoamericana, destacan ampliamente las figuras de Bolívar y San Martín y en el grupo que les sigue posiblemente O’Higgins sea uno de los más apreciados. Un ejemplo, en el libro de Bushnell y Macaulay, una rápida revisión de sus páginas entrega alrededor de 25 citas a Bolívar y 3 a San Martín tanto como otras 3 a O'Higgins, y, en ambos casos, respecto a acciones muy concretas ${ }^{20}$. Casi excepcionalmente, en la obra de Robert Harvey dedicada a los libertadores, junto a Miranda, Bolívar, San Martín, las páginas sobre O’Higgins, su vida, obra, acción política y militar son abundantes y el propio proceso de

\footnotetext{
17 Lynch, John. 1984. "Los caudillos de la Independencia: enemigos y agentes del Estado Nación”, en Buisson, Inge, “Problemas de la formación", p. 191-193.

18 Mitre, "Historia de San Martín", p. 978-979.

19 Ibídem, p.982

${ }^{20}$ Bushnell, David y Macaulay, Neill. 1989. El nacimiento de los países latinoamericanos, Madrid, Nerea.
} 
independencia chilena alcanza alrededor de un $20 \%$ o más del libro ${ }^{21}$. En el caso específico del Perú, en una de las obras importantes de Aljovín de Losada, que estudia el proceso de Independencia proyectándolo por algunas décadas, lo que permite observar no sólo presencias efectivas, sino también influencias de personajes destacados, éste muestra en primer lugar la gran actividad de Simón Bolívar a través de 95 referencias; le siguen Agustín Gamarra con 78 y Andrés de Santa Cruz con 62. José de San Martín no queda demasiado atrás al marcar 47 referencias $^{22}$. Por cierto, esta situación refleja las consecuencias para San Martín por su opción respecto a la monarquía frente a la república. Igualmente, es comprensible la ausencia de O'Higgins y no sólo en este libro, sino por sus reconocimientos nebulosos que podemos observar en tiempos posteriores.

De manera evidente, se trata especialmente de una cuestión espacial y de fuerza en los conceptos y tratamientos de lo que se pensaba como la revolución americana y el surgimiento de un americanismo que traspasara fronteras y creara una relación de hermandad y solidaridad. De hecho, todos los ensayos unionistas que surgieron a partir de 1822 respondieron no sólo a la amenaza externa, a la formación de un ejército común y a evitar conflictos internos entre los nuevos Estados apelando a la existencia de un Congreso de representantes con facultades arbitrales. El sueño de la unión americana. Como lo hemos advertido en líneas anteriores, especialmente en el caso del Cono Sur, desde lo americano, rápidamente se produjo el fomento de diferenciación de las nuevas Repúblicas.

De hecho, el proyecto de confederar a las nuevas repúblicas se inició inmediatamente en forma posterior a la creación de Colombia (Gran Colombia) en 1821, "cuando Simón Bolívar envía dos emisarios a Centro y Sudamérica con la misión de suscribir sendos tratados bilaterales de unión, liga y confederación perpetua" ${ }^{23}$. Uno de ellos, el senador Joaquín de Mosquera, el 6 de junio de 1822, firma el tratado con Bernardo Monteagudo, encargado de relaciones exteriores del Perú; el segundo, con Joaquín de Echeverría y José Antonio Rodríguez, representantes de Chile el 21 de octubre de 1823; y, en el mismo año, en Argentina, con Bernardino Rivadavia sólo llega a suscribir un acuerdo de amistad y alianza. En octubre de 1823, Miguel Santamaría, por Colombia, firma con Lucas Alamán de México y el 15 de marzo de 1825; Pedro Molina, representante de Centroamérica, hace lo propio con el canciller colombiano. En lo que respecta a Perú y Chile,

\footnotetext{
${ }^{21}$ Harvey, Robert. 2010. Los libertadores. La lucha por la independencia de América Latina, 1810-1830, Barcelona, RBA Libros.

${ }^{22}$ Aljovín de Losada, Cristóbal. 2000.Caudillos y Constituciones. Perú: 1821 - 1845, Lima, Instituto Riva-Agüero PUC y FCE, pp.319-328.

${ }^{23}$ de la Reza, Germán. 2012. El ciclo confederativo. Historia de la integración latinoamericana en el siglo XIX, Lima, Universidad Nacional Mayor de San Marcos, p. 23.
} 
“El acuerdo firmado con el gobierno de José de San Martín poco antes de su salida del Perú... da cobertura al arribo de Bolívar al frente del Ejército Libertador y quiere establecer un vínculo indisoluble entre la independencia y el unionismo hispanoamericano. El acuerdo Colombia-Chile estimula la creación de otro acuerdo: el Tratado de Confederación ChilePerú, único producto de las recomendaciones de Bolívar de promover nuevos acuerdos confederativos" $^{24}$.

Sabemos que el siguiente paso, entre otros acontecimientos, la convocatoria al Congreso de Panamá no estuvo exento de problemas y que, en definitiva, si bien es cierto fue una real motivación para un importante proyecto de asociación entre los nuevos países, reflejó, por el contrario, la seria disposición de cada Estado a tener sus propias fronteras e historias ${ }^{25}$.

O’Higgins tenía un fuerte espíritu americanista, pero focalizó sus objetivos de lograr la formación de una nueva nación en el caso particular de Chile. Alejado del poder (y de las decisiones políticas) poco o nada podía hacer en beneficio de relaciones de hermandad chileno-peruanas y menos pensando en el Congreso de Panamá que seguramente todavía lo veía lejano. Además, las rencillas internas y las desconfianzas hacia Bolívar igualmente influyeron en términos del afianzamiento de las propias identidades. No hay que olvidar, además, las tradicionales disputas entre la elite santiaguina colonial con los criollos limeños del sistema colonial, particularmente en la segunda mitad del siglo XVIII.

San Martín, por su parte, no tuvo que decidir entre sus razones americanas y sus razones argentinas, chilenas o peruanas. El acuerdo hacia el proyecto de unión de Bolívar firmado poco antes de su salida del Perú, posibilitando el arribo de este último hasta la propia Lima, tampoco precipitó una orientación hacia acuerdos mayores de carácter federativo entre las naciones. Rápidamente, las tensiones entre Bolívar y Francisco de Paula Santander o los posteriores conflictos a propósito de las decisiones de Antonio José de Sucre y la independencia de Bolivia en 1825 , puso en mal pie las relaciones entre peruanos y colombianos. Las contingencias políticas del nacionalismo que maduraba rápidamente provocaron que los ideales americanistas o panamericanistas fuesen ideales sin proyecciones inmediatas.

Por cierto, la situación alcanzó a nuestros personajes. O'Higgins se radicó en Lima y seguramente por su marginación de la política activa, fue bien recibido y reconocido en sus esfuerzos de preocupación por el Perú durante los años de su gobierno. San Martín fue aún más considerado, especialmente a partir de los años siguientes, porque lejos, en Europa, sólo quedaban sus éxitos militares y su legado. Seguirá cosechando las honras de su acción y sus sacrificios personales en la memoria de la sociedad y en el panteón de los héroes peruanos.

\footnotetext{
${ }^{24}$ Ibídem, p.25,

${ }^{25}$ En extenso, ver los trabajos de Germán A. de la Reza. El ya citado anteriormente y La invención de la Paz. De la República cristiana del Duque de Sully a la sociedad de naciones de Simón Bolivar, México, Universidad Autónoma Metropolitana-s XXI, 2009.
} 
Para O’Higgins la situación fue diferente. Siendo también arquitecto de la independencia del Perú, no fue su constructor ni asumió el carácter de héroe local. Apreciado en círculos particulares de la bullente Lima, beneficiado sin duda alguna por las reales consideraciones hacia su papel de gestor en la Independencia del país, en la memoria histórica peruana debió también, como chileno, soportar el peso de las graves situaciones de alejamiento entre ambas naciones al calor de diferencias en los intereses, especialmente económicos, entre privados y su correlación con sus respectivos Estados, que llevaron a las armas ya en la década de 1830 y, muy particularmente, con la guerra del Pacífico. El recuerdo peruano de O’Higgins, colectivamente, ha pasado entre brumas y claridades y, por lo tanto, en espacios poco nítidos en la historia y la historiografía del país. No obstante, igualmente hay que considerar que, en su propio tiempo, la respuesta del Perú al exilio de Don Bernardo en Lima fue no sólo de reconocimiento, sino también de gran generosidad al proveerle de los medios para su subsistencia de acuerdo con sus méritos e historia. En todo caso, sólo en noviembre del año 2005, en una visita oficial del comandante en jefe del Ejército chileno a Lima, su busto pasó a formar parte de la galería de los héroes peruanos que conforma solemnemente el Panteón Nacional.

Pero, a no equivocarse, los héroes no siempre mantienen sus posiciones en la escultórica pública de sus países. En los últimos años, de acuerdo con posiciones políticas contingentes, don Bernardo no ha estado exento de discusiones en Chile e igualmente ha tenido que soportar las réplicas de las discusiones sobre el pasado que ayudó a construir ${ }^{26}$. Como sea, O’Higgins y San Martín - San Martín y O’Higgins, héroes nacionales y americanistas.

\section{Referencias bibliográficas}

\section{Fuentes}

Mitre, Bartolomé. 2011. Historia de San Martín y la emancipación sudamericana, Buenos Aires, Editorial El Ateneo.

O’Higgins, Bernardo. 1985. "A los habitantes del Perú, setiembre de 1820", en Romero, José Luis, Pensamiento Político de la Emancipación, 1790-1825, Barcelona, Biblioteca Ayacucho, T.2.

San Martín, José de. 1985. "A los limeños y habitantes de todo el Perú, 13 noviembre 1818", en Romero, José Luis, Pensamiento político de la Emancipación, 1790-1825, Barcelona, Biblioteca Ayacucho, T. 2.

\footnotetext{
${ }^{26}$ Ver, al respecto, Guerrero, Cristian y Cárcamo, Ulises. 2013.“O’Higgins entre izquierda y derecha”, Cuadernos de Historia, Vol. 39, Santiago, p. 113-146.
} 
San Martín, José de. 1985. Proclama al Congreso Constituyente dimitiendo el mando supremo, 20 septiembre 1822 y Proclama de despedida, 22 septiembre 1822, en Romero, José Luis, Pensamiento político de la Emancipación, 1790-1825, Barcelona: Biblioteca Ayacucho, T. 2.

\section{Referencias citadas}

Aljovín de Losada, Cristóbal. 2000. Caudillos y Constituciones. Perú: 1821-1845, Lima, Instituto RivaAgüero PUC y FCE.

Basadre, Jorge. 2002. La iniciación de la República (1929), Cásicos sanmarquinos, Lima, Fondo Editorial de San Marcos, T. I.

Bushnell, David y Macaulay, Neill. 1989. El nacimiento de los países latinoamericanos, Madrid, Nerea.

De la Puente Candamo, José A. 2001. "La historiografía peruana sobre la Independencia en el siglo XX", en O'Phelan, Scarlett (comp.), La independencia del Perú. De los Borbones a Bolívar, Lima, Instituto Riva Agüero, PUC.

De la Reza, Germán A. 2009. La invención de la Paz. De la República cristiana del Duque de Sully a la sociedad de naciones de Simón Bolívar, México DC, Universidad Autónoma Metropolitana, S XXI.

De la Reza, Germán A. 2012. El ciclo confederativo. Historia de la integración latinoamericana en el siglo XIX, Lima, Universidad de San Marcos.

Gelman, Jorge (Dir. y Coord.). 2010. Argentina. Crisis imperial e independencia, Madrid, MAPFRE. Guerrero L., Cristian y Cárcamo S., Ulises. 2013. “O'Higgins entre izquierda y derecha”, Cuadernos de Historia, Vol. 39, Santiago, pp. 113-146.

Harvey, Robert. 2010. Los libertadores. La lucha por la independencia de América Latina, 1810 1830, Barcelona, RBA Libros.

Kossok, Manfred. 1984. "Revolución, Estado y Nación", en Buisson, Inge (Ed.), Problemas de la formación del Estado y de la Nación en Hispanoamérica, Bonn, InterNations.

Lynch, John. 2009. "Los caudillos de la Independencia: enemigos y agentes del Estado Nación”, en Buisson, Inge (Ed.), Problemas de la formación del Estado y de la Nación en Hispanoamérica, Bonn, InterNations.

Lynch, John. 2009. San Martín. Soldado argentino, héroe americano, Madrid, Crítica.

Romero, José Luis. 1985. Prólogo, en Romero, José Luis, Pensamiento Político de la Emancipación, 1790-1825, Barcelona, Biblioteca Ayacucho, 2 T.

Romero, José Luis. 2009. Breve historia de la Argentina, 8ª edición, Buenos Aires, FCE. 